\title{
The 'Bush Capital' - A Review of 100+ Years of Integrative Spatio-Temporal Planning for a City in the Landscape and Nature in the City
}

\author{
A. Jasmyn J. Lynch 1,2 (D)
}

check for

updates

Citation: Lynch, A.J.J. The `Bush

Capital'-A Review of 100+ Years of Integrative Spatio-Temporal Planning for a City in the Landscape and Nature in the City. Land 2022, 11, 169. https: / / doi.org/10.3390/ land11020169

Academic Editors: Thomas Panagopoulos and Guillermo J. Martinez-Pastur

Received: 28 November 2021

Accepted: 14 January 2022

Published: 21 January 2022

Publisher's Note: MDPI stays neutral with regard to jurisdictional claims in published maps and institutional affiliations.

Copyright: (C) 2022 by the author. Licensee MDPI, Basel, Switzerland. This article is an open access article distributed under the terms and conditions of the Creative Commons Attribution (CC BY) license (https:// creativecommons.org/licenses/by/ $4.0 /)$.
1 Environment, Planning and Sustainable Development Directorate, ACT Government, Canberra, ACT 2601, Australia; Jasmyn.lynch@act.gov.au or ajj.lynch@gmail.com

2 School of Culture, History \& Language, College of Asia and the Pacific, Australian National University, Canberra, ACT 2601, Australia

\begin{abstract}
Over approximately 100 years, the Australian capital, Canberra, has evolved in association with the predominant values, vision and cultural relationships of people to the area. The location and design of the city derived from a formal intention to integrate nature and culture for the benefit and edification of residents and in symbolisation of the city's importance as the seat of national decision-making and legislature. Established on a native grassland surrounded by wooded hills and ridges, and with nearby confluences of rivers as security of water supply, the city's landscape was transformed through centralised planning and implementation of Garden City and City Beautiful constructs to become one of the world's most liveable regions. Twentieth-century expansion of the city's suburbs, tree streetscapes and gardens progressed with varying emphasis on exotic versus native species, and contemporary programs aim to increase urban tree canopy cover to $30 \%$. Yet, there is increasing acknowledgement of the landscape's rich history of culture-nature interactions extending back at least 25,000 years. Indicators are evident in human modification of tree-dominated ecosystems, the overlapping ways in which people related to elemental landscape features, and a continuity of valuing particular sites for ceremonies, social activities and human movement. With projected steady population growth, climate change, and associated impacts on the environment and natural resources, contemporary planning must be innovative and integrative to ensure ecologically sustainable development. Strong visionary leadership is needed to develop a landscape policy that encompasses key natural assets including threatened woodlands and mature native trees for their intrinsic values and as habitat for threatened fauna, cultural landscape values such as forested montane and ridge areas, and heritage and protected trees. From pre-European to current times, planning, modification and management of environmental and ecosystem values has been integral to enabling local people to sustain themselves. The next challenge is to create clarity about the future of this cultural landscape and enhance the community's attachment to and stewardship of the city and its landscape.
\end{abstract}

Keywords: treescape; urban planning; Canberra; community; First Nations; development; biodiversity conservation

\section{Introduction}

Integrative planning, clear objectives and an understanding of human agency and relationships to the landscape are necessary to achieve long-term environmental and ecological outcomes. This is particularly so in the urban context where biodiversity and ecosystem services are recognised as essential for human wellbeing but directly and indirectly impacted by infrastructure development and increasing pressures on natural resources. The relationship between people and natural elements, or culture and nature, is a major theme underpinning modern understandings of the cultural landscape paradigm [1]. Cultural landscapes include the tangible, built components but also the intangible associative values, 
such as being the space for human activity (culture) and experiences, and the ideological and political phenomena that shape society and the cityscape spatially, temporally and experientially [1]. Despite being inextricably dependent on nature, a particular society can dramatically alter a region's ecology and reshape nature as one group takes over or penetrates another group. This 'ecological imperialism' can be manifested through conscious policies, and passively with an influx of crops, weeds, germs and pests [2]. It has been particularly evident in relation to global exploitation and disturbance of forests, with deforestation generally increasing in parallel with population growth [2].

Recognition of the importance of nature and international, national and regional mechanisms focused on biodiversity conservation and ecologically sustainable development have not prevented the global decline of biodiversity at rates unprecedented in human history [3,4]. This is the case even within developed, well-resourced countries in both terrestrial and aquatic landscapes [4]. The primary drivers of ecosystem degradation and biodiversity loss are failures in governance, leadership and stewardship that have not prioritised coordinated, integrative planning, implementation and evaluation [5,6]. McNeely [7] (p. 265) stated that 'all biodiversity problems reflect a conflict of interests between alternative uses of resources' since conservation values are just one of the diversity of interests needing to be balanced by politicians and decision makers. 'Mainstreaming' or internalising of biodiversity into policies, programs and behaviour in regional planning has been promoted as a solution $[4,6,8,9]$ and aligns with the first principle of the Rio Declaration on Environment and Development, which specified a clear linkage between healthy, productive humans living 'in harmony with nature'. However, the worsening outcomes show that policy and management need to be adaptive, actively address pressures and manage risks, and challenge the dualistic separation of conservation and production outcomes that lead to the non-viability and loss of valued elements [10].

Compartmentalised decision making and perspectives can undermine sustainability [5], which reinforces the importance of leadership and participatory engagement in planning. These are needed to create a shared vision, change perceptions and enable knowledge synthesis, while also building a supportive organisation and the necessary political support [5]. Recognising that there are a multitude of pathways in decision making and interactions between them, Ruckelshaus et al. [11] posited that small iterative approaches can be effective by engaging stakeholders in exploring the implications of novel policy approaches for changes in biodiversity, ecosystem services and human wellbeing and then ultimately integrating the values of nature into specific policies, plans and projects. Yet, because policies to conserve biodiversity tend to challenge social and economic behaviour by altering or restricting access to resources, the 'small wins' in biodiversity conservation must contribute to an overall strategy and systemic macro-level changes to facilitate transformative change towards sustainability [7].

In the Australian Capital Territory (ACT), the location of the Australian capital city of Canberra, a wide range of strategies, plans and legislation are in place relating to biodiversity conservation and environmental sustainability. Nevertheless, the city's population of 430,000 is projected to reach 700,000 by 2058 [12], placing substantial pressures on the regional environment. This article explores the changing landscape of Canberra, with a focus on tree-dominated ecosystems, by outlining the evolution of key planning stages. The city is exemplary in integrating nature and culture through its history of deliberative planning with the landscape defining and playing an intrinsic role in the city's design and social wellbeing [1]. While there are other cities, such as Zurich and Kyoto, that feature landscape open space around and within the urban area, the landscape context and environmental values of Canberra were embedded within its foundational vision and subsequent planning $[13,14]$. The article draws on consideration of cultural landscape characteristics, the role and value of native and exotic species in the local landscape and urban context, and the importance of leadership in achieving transformative change. Key challenges for achieving biodiversity and sustainable development outcomes are discussed with conclusions for future regional planning needs. 


\section{The Planning of a City in the Landscape}

Canberra has been a highly planned city from its inception in 1913, and this intensive planning history has differed from the development of other Australian cities. The city and its national significance were born from the federation of Australia in 1901, which united six self-governing colonies to form the Commonwealth of Australia. The Australian Constitution developed in 1901 required the creation of a national capital.

The subsequent eight-and-a-half-year search for a suitable site for the new federal territory explored various regions across south-eastern Australia, eventually settling, after protracted inter-governmental negotiations, on the present location because of its complex topography, shelter from cold winter winds, and capability of protecting water quality and storing water for ornamental purposes [13]. It was originally intended to include the catchments of two main rivers (Molonglo and Queanbeyan) to prevent their pollution upstream of the city $[13,15]$. The layout of the city was similarly highly planned, the outcome of an international competition commissioned by the new federal government in 1911-1912 with designs superimposed on a recent contour map of the future city area. Submissions were expected to embody in their designs all recent developments in the science of town planning [16].

The site selection and design competition focused attention on the role of landscape in the modern city and key elements of the emergent town planning movement. These included the British 'Garden City' movement, which emphasised spacious informality of concentric greenbelts, clusters of self-sufficient communities, with short commuting times and healthy, uplifting living conditions for the whole community $[16,17]$. Another key influence was the Euro-inspired American 'City Beautiful' movement, which focused on grandeur, civic pride, enhanced sanitation and traffic circulation engendered through stately boulevards, parks and public spaces. It encapsulated a belief that such grandeur and beautification improve the landscape and inspire moral uplift and civic virtues. The submitted designs were perceived to reflect a sense of 'space, light, and open space as pillars of healthiness, social efficiency, and general quality of life' [17] (p. 7).

The selected design plan by Americans Walter Burley Griffin and Marion Mahony Griffin was greatly influenced by topographical and landscape considerations. Two symmetrical land and water axes aligned with four local mountain summits and crossed the city to link nationally significant building sites in conspicuous positions against the forested landscape as a backdrop (Figure 1). The Griffins had not yet visited the site but their design encapsulated a vision of Canberra being a 'city in the landscape', nestled amongst forested hills and situated astride the impounded waterway of the Molonglo River with aesthetic formal water basins as a centrepiece (now Lake Burley Griffin) that also augmented humidity and equability. Griffin's [18] explanatory design report referred to 'great garden and water vistas', 'connected park or garden frontage for all the important structures', 'common gardens, irregular hill garden subdivisions', streets with 'stately open-branched, broad-leaf evergreen avenue trees', 'quadruple rows and supplemental shrubbery parkways for shade and shelter, wind and dust arresting' and 'beneficial sunlight'. Public spaces, national monuments, boulevards, and architectural features reflected a focus on grandeur, aesthetics and a democratic purpose of 'the greatest good for the greatest number'.

Incorporation of special views that reflect the local character and cultural context is a key consideration in defining a cultural landscape [1]. This is achieved in Canberra by maintaining continuity with key original design elements of the landscape's hills, ridges and valleys. More uniquely, the mixing of built infrastructure, natural infrastructure and plantings of stately exotic trees along with Australian native trees underlies the designation of the city as the Australian 'Bush Capital' [19]. Regardless, its implementation and grandiosity was challenged early on by government officials and through disinterest from politicians and the public $[13,15]$. 


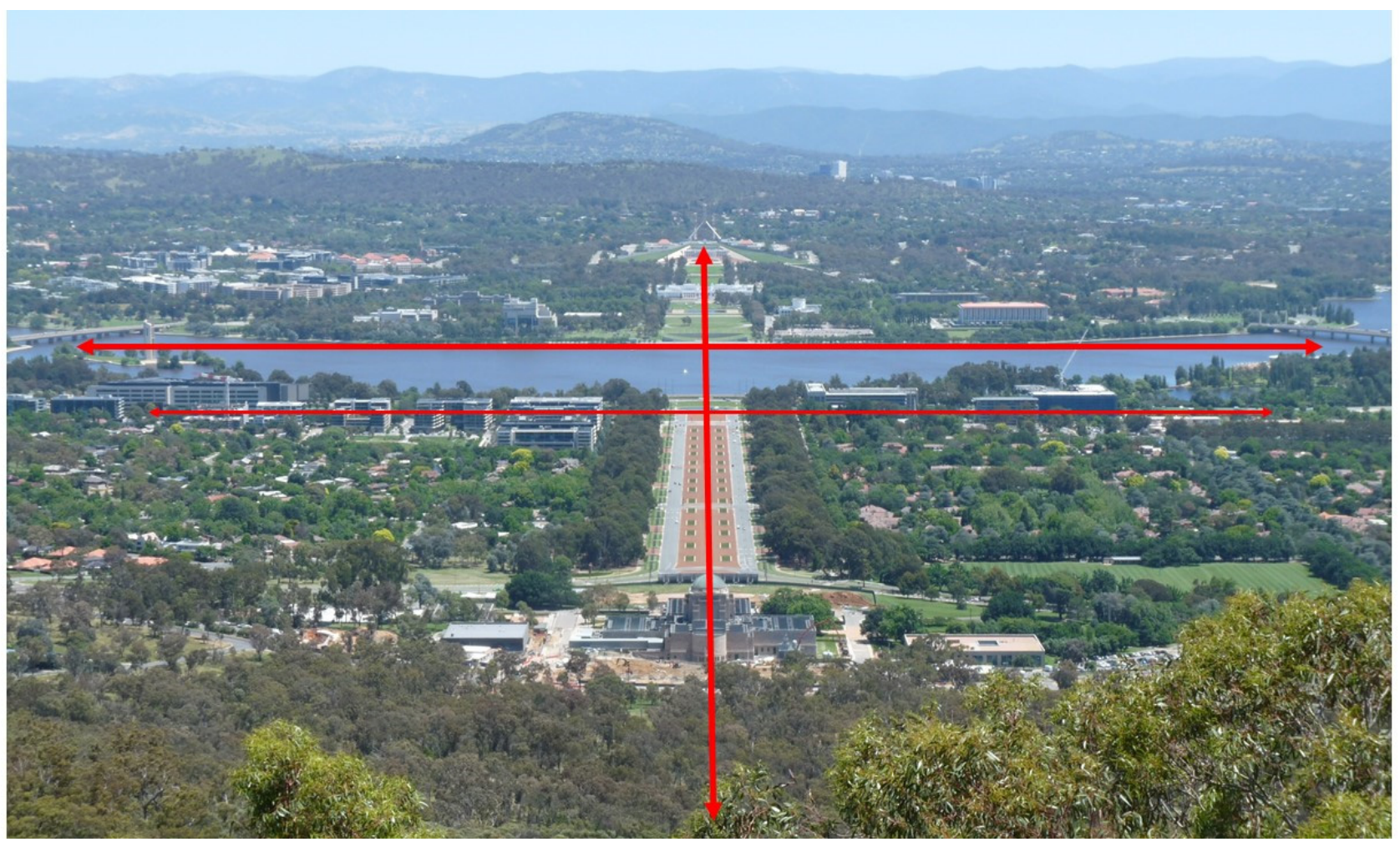

Figure 1. View of central Canberra, showing the Land Axis (vertical) between Mt Ainslie and Parliament House on Capital Hill, the perpendicular Water Axis (upper horizontal line) across Lake Burley Griffin, and a secondary Municipal Axis originally intended to form an avenue of municipal buildings. The olive- or brown-coloured tree canopies are typically of native Australian species whereas the green canopies are primarily exotic species.

The importance and need for protection of the intent and symbolism of the original urban design legacy was recognised in 1964 by the Commonwealth Government [20]. The ACT's network of open space was formally conceptualised as Canberra's National Capital Open Space System (NCOSS) and incorporated into planning regulation through the 1970s and 1980s [20]. The NCOSS comprises the treed inner hills and ridges, the major (artificial) lakes and river corridors, and the views of mountains and bushland to the west of the city, with the region's rural lands also part of the landscape setting. It now covers over two-thirds of the ACT [17].

Despite the ACT gaining self-government in 1989, the NCOSS was retained under control of the Commonwealth Government and legislated as 'designated land' under the National Capital Plan (1990, 2012). This unique land tenure arrangement means that all land is owned by the Commonwealth Government and leased to landholders, thereby preventing uncontrolled private development [21]. The National Capital Plan regulates development to preserve and enhance 'landscape features that give the national Capital its character and setting' while promoting local urban development that respects environmental values and sustainability [20]. The Territory Plan is the key statutory planning framework for the ACT but cannot be inconsistent with the National Capital Plan.

Just over 100 years after its conception, and with its population and extent far exceeding the original design, careful planning continues to be essential to ensure the city's liveability and the integrity of its vision for the next 100 years. Increasing pressure for urban densification, urban consolidation and high-rise buildings needs to be carefully managed to retain the open space, grandness, views of the surrounding hills and living infrastructure that are quintessential to Canberra's historic urban landscape foundation and its nature-culture interface [1,19]. An additional new imperative is the need for urban climate change adaptation. Meanwhile, the connection to the landscape of Canberra's First 
Nations people may be fundamental to achieving long-term biodiversity conservation and ecologically sustainable development.

\section{Changes in Drivers of the Landscape and Its Forest Values}

Forested ecosystems have increased substantially in the Canberra region since settlement by Europeans, with varied focus through time on their extent, stand density and degree of 'naturalness'. A mosaic now exists of relatively 'natural' ecosystems (e.g., in nature reserves), modified or transitional vegetation (e.g., in public open space) and novel vegetation (e.g., in urban areas). The transition can be described in four phases: (i) pre-European settlement; (ii) colonial settlement; (iii) developing the grand vision; and (iv) suburban expansion and plan consolidation. These phases demonstrate the strong influence of people in shaping the region's landscape and the contrast with the typical global increase in deforestation with population growth [2].

\subsection{Ngunawal Traditional Custodians}

The ACT has a long history and, despite a harsh climate, reliable resource availability. Carbon dating affirms that the Traditional Custodians, the Ngunawal ${ }^{1}$ people, were in the landscape approximately 25,000 years ago at Birrigai rock shelter in the foothills of Namadgi National Park [22,23]. Upland montane areas of the park, which are more climatically severe, were being actively utilised from around 8000 years ago as post-glacial conditions ameliorated [23]. Feasting on aestivating Bogong Moths (Agrotis infusa) in montane areas during summer was accompanied by social and ceremonial activities [22]. In contrast, the more climatically moderate tableland where Canberra is located (564 m altitude) provided a range of plants useful year-round as food, cordage, dye, gum, fish poisons, timber for spears, roofing, boomerangs, and bark for canoes, as well as various fish, marsupials and native rodents, reptiles and birds that also provided food, and some utilitarian items [24,25].

Reliability of food and water was essential for Ngunawal people as evidenced by the siting of some large campsites along major waterways [26]. Ecotonal areas, valleys and riverine areas were more intensively or frequently occupied due to water availability and more abundant flora and fauna resources $[26,27]$. Local creeks were typically a chain of ponds lined with trees and shrubs and flowed rapidly only in flood [26]. Woodlands of large, scattered Eucalyptus trees (e.g., Yellow, Red and Apple Box; Red Gum; Stringybark) with a grassy groundcover dominated the lower slopes, while grasslands occupied low-lying areas with intense frosts or waterlogging [28]. Ridges above $640 \mathrm{~m}$ elevation supported open Eucalyptus forests of Stringybark, Scribbly Gum and Brittle Gum over a grassy understory when frequently burnt by Ngunawal people or a more closed canopy and shrubby understory with less burning [21,26]. Fire was used by First Nations people in south-eastern Australia to attract herbivores to fresh growth, drive out game for hunting, to increase tuberous plants as staple foods, clean country and clear pathways [25,29].

Population estimates suggest around 400-500 Ngunawal people may have occupied the Canberra area when Europeans first arrived. With over 200 campsites identified so far $[19,25]$, this number is likely to be an underestimate. Indeed, the site of the modern Australian Parliament was a camping ground for the Ngunawal people [30], and a meeting place and ceremonial site where different tribal groups would come together [31]. Their system of pathways traversed between significant places such as tribal meeting areas, campsites, resource areas, and for travelling to other parts of their Country (landscape) and major spiritual and gathering places further away; the main pathways followed watercourses and the ridges and spurs of hills and mountains [26,30,31]. It is notable that the generally accepted meaning of the Ngunawal name for the Canberra area is 'meeting place' and that it is now the seat of national government [25]. 


\subsection{Colonial Settlement}

European settlement of the Canberra region (then known as the Limestone Plains) began after the earliest known explorers arrived in late 1820. The explorers were looking to confirm the presence of a large lake (now Lake George) and large river (the Murrumbidgee) of which they had learned from First Nations people [13]. Charles Throsby in 1821 described extensive plains with 'rich meadow land on the banks of the rivers' [32]. Notably, early explorers, settlers and shepherds used the Ngunawal pathways [32] while some early settler's homesteads were built near or upon Ngunawal people's campsites $[19,26]$.

Colonial settlers followed soon after, moving out from Sydney 200 miles away, which was already experiencing overstocking and drought. They focused on establishing large estates for grazing and some cropping near the Molonglo River [19,32]. By 1828, 72 Europeans had relocated to the region [32]. Authorised land grants from 1824 to 1834 centred on the reliable major watercourses and grassy alluvial flats, but many were controlled by station managers or stockmen for absentee owners $[15,26]$. The area's good grazing enabled one station-hand, Ainslie, to increase his flock from 710 to 20,000 sheep in nine years [32,33].

Legislative change in 1860 gave rights over smaller land blocks (around 30 hectares) in-between the large estates to be taken up by free selectors (farmers, squatters and dairymen) and tradesmen (millers, brickmakers, carpenters, blacksmiths, splitters, sawyers and fencers). This led to intensified land use for settlement and grazing, timber cutting for fencing and firewood, clearing to increase the area of grass for grazing, and cropping in cleared areas $[26,34]$. The grassy woodlands were cleared for grazing and the dry forests on the hills and ridges were thinned or cleared [32]. For example, the slopes of Black Mountain (originally thinly wooded, now densely wooded) and Mount Majura were heavily cleared, burnt and grazed $[15,33,35]$. The increased slope runoff degraded the swampy lowlands and 'chain of ponds' on the plains and caused gully erosion [32]. Grazing impacted on the biomass and diversity of groundcover plants and tree regeneration [36].

Extirpation of many native fauna followed, including of the Brolga, Bustard, Brush Turkey and Emu [26,32], with later incursions of feral animals, primarily foxes and cats, causing local extinction of various small marsupials and declining fish and bird species. Overfishing rapidly reduced the local fish fauna too [15]. Tree distributions altered also; the Stringybark Eucalyptus macrorhyncha no longer occurs on Mt Majura where it was listed in 1886 while Casuarina stricta has disappeared from areas where it was cut out or used as grazing fodder [35].

The traditional lifestyles of the local Ngunawal people also rapidly diminished and changed after European settlement, with many enduring forced movement onto missions or reserves. Despite this, some Ngunawal Elders continued to recount their cultural Dream Time stories and to visit and maintain their sacred sites and cultural responsibilities [27,30,37] (pp. 5, 30). Ample evidence of their cultural longevity and continuity is in stone arrangements, scarred trees, grinding stones, artefact scatters, stone and ochre quarries, and rock art paintings including at sites now under the city and lake $[30,31]$. As the world's oldest living culture, even today, as recounted by Ngunawal Elders Wally Bell and Karen Denny in 2018, the culture of Ngunawal people spiritually draws them back to their significant cultural places to reconnect with the Dream Time. An ongoing connection to Country is an important part of Ngunawal culture and identity, manifested through active management and custodianship.

\subsection{Developing the Grand Vision}

In 1909, the site selected for the national capital was a windswept dusty plain with a scattering of European trees such as willows, elms, oaks and pines planted along river margins and around homesteads [34]. Oaks and willows provided stock fodder during drought periods [33].

With little known of the suitability of trees to the local climatic and soil conditions, Charles Weston was appointed in 1913 as head of afforestation to select tree and shrub 
species for landscaping the city. Weston had migrated from England only 17 years earlier and had a difficult challenge because of the region's infertile soils, the degradation from overstocking, exposure to westerly winds, low humidity, and severe, frosty winters but hot, dry summers with total rainfall as low as $326 \mathrm{~mm}$ in 1913 [16]. Weston experimented with sowing, raising and planting over 600 tree, shrub and crop (fruit, vegetables, grains) species, including non-locally occurring plants from across Australia and others from Europe, America and the Middle East. He kept detailed records of his seed sources and of trees native to the Territory. Formal plantings included plantations and corridors of Redwood (Sequoia sempervirens, S. giganteum), Roman Cypress (Cupressus sempervirens), American Elms (Ulmus americana) and Poplars (Populus spp.) [19]. He recommended fireresistant trees (e.g., poplar, elms and willows) to mitigate local bushfire risk and trees to support tanning and stock feed [16]. Plantations of Monterey and Ponderosa pines commenced in 1915 as an economic resource [21].

Between 1912 and 1920, Weston coordinated 820,000 plantings, although possibly three-quarters were lost to drought or failed to establish [16]. The year 1920 marked the end of Griffin's oversight of the city's design and construction, which at that time consisted primarily of infrastructure for power supply, water storage, sewerage and road construction. An advisory committee was established to oversee plantings in the streets and avenues [16].

The Canberra region is significant for other plant experimentation. In the late 1800s, crossbreeding of wheat varieties by the English immigrant William Farrer led to the development of a hybrid with increased resistance to rust disease. The new type was named 'Federation' after the 1901 creation of the Australian nation $[33,38]$.

From 1921 to 1926, new policies and attitudes to vegetation were developed. Weston and the advisory committee instigated a range of initiatives and recommendations including the planting of over one million trees, the restriction of lawns to public gardens and public building surrounds due to their establishment and maintenance costs, a principle of linear plantings along avenues and roads but irregular groupings for parks, hedges as front boundaries rather than fences, and free plants for new home-owners and farm lessees [16]. Residential gardens were recognised as important components in achieving a world-leading garden city [16]. Retention of trees during engineering and building works also became topical, as reflected in an instruction from the Federal Capital Commission, established in 1925, to the Chief Engineer: no trees were to be cut down or trimmed wherever avoidable anywhere in the city plan or within 200 yards of the city's main entrance roads without official approval [16].

Affiliation and commemorative plantings featured from 1926 with community, businesses or visiting dignitaries presenting trees for planting in main avenues and special locations [16]. A botanic garden was initiated in 1933 (but not publicly opened until 1970) to establish native plants and lead in their study and usage in urban landscaping, with additional annexes from 1951 at the coast for plant acclimatisation and another for alpine vegetation [16,21]. A rainforest gully was enabled in the botanic gardens in 1974 by installation of a misting and irrigation system. The region's first flora and fauna reserve, now Tidbinbilla Nature Reserve, was proposed in 1935 although the land reservation took until 1950 [16]. Plantings of two local Eucalyptus trees in the grounds of Parliament House marked the jubilee year of 1951 along with 40,000 trees and shrubs in public areas and 20,000 in residential gardens [16]. Altogether, by 1964, almost three million trees and shrubs had been planted in Canberra [21].

\subsection{Suburban Expansion and Plan Consolidation}

From a population size of around 800 in 1851 and 1921 individuals in 1911, Canberra grew to 5870 residents by 1927 [16,33]. The national parliament opening in Canberra in 1927 and construction of permanent housing from 1926 led to an influx of civil servants [30]. The population swelled again with immigration after World War II and a Commonwealth Government policy of 1948 to transfer various departments to Canberra [30]. The propor- 
tion of public officials compared to other sectors was (and remains) considerably greater in Canberra than in other Australian cities [21].

The National Capital Development Commission (NCDC) was established in 1957 to continue urban planning. The NCDC reinforced the objectives of a 'large park-like landscape' and garden city residential standards in its first five-year plan [17]. It developed criteria for provision of parkland and open space of 4 ha per 1000 people, which was subsequently apportioned for active and passive recreation [34]. Changes in attitude to recreation and flexible use led to an integrated open space system that linked open space with parkland [34]. Canberra provides one of the world's most generous extent of parkland and public open space for a city [34].

A landscape planning unit was formed in the mid-1960s with a native tree orientation [39]. Information was provided to residents about suitable species, gardening advice and the annual plant issuing program [17]. Land-use designs were developed to extend the city from the original plan for 75,000 residents to a population of 250,000 [21]. Districts in the valleys were linked by arterial roads and surrounded by vegetated hills, ridges and parklands extending west to the mountains.

Notably, in 1949, original plantings of American Elms and poplars along the primary road entrance to the city along Northbourne Avenue were replaced by local trees, Eucalyptus blakelyi and E. mannifera, demonstrating a growing acceptance of native species in horticulture [19]. A consultative committee on parks and gardens in 1944 argued for an Australian orientation in tree planting [16]. However, a strong ratio of almost four times the number of exotic species as native species was planted between the 1920s and 1950s [40]. It was not until the 1970s that plantings in some new suburbs were dominated by or exclusively native species [40]. This culminated in the 1980s with large-scale plantings of Australian trees, shrubs and groundcover plants in the Parliamentary zone around iconic national buildings including the High Court, National Gallery, the National Portrait Gallery and the new Parliament House, which was completed for the national bicentennial in 1988 [39].

A distinction between native and local Australian plant species is important as the Northbourne Avenue corridor was supplemented in 1987 with planting of the non-local E. elata [19]. This tree selection focused on the aesthetic feature of drooping foliage rather than careful site selection as the species prefers deep moist soils and is only drought and frost tolerant once established. Similarly, the plantings around the national buildings were often native but not endemic to the Territory, being chosen for their stature and flowers.

Although the plantings in the Parliamentary zone were primarily aesthetic, they also purportedly represented participatory democracy [39]. Various exotic deciduous trees, notable for their autumnal leaf colour and now an autumnal tourist attraction, were planted in the 1960s, with pines and conifers planted as accents. Lombardy Poplars, White Poplars and English Elms were chosen for their yellow autumn leaves and later supplemented by the reds and browns of Pin Oaks, Liquid Ambers and Claret Ash [21]. The columnar form of poplars also emphasised the structure of adjacent iconic buildings such as the National Library and original Parliament House [19]. Meanwhile, a formal rose garden was developed with roses donated by rose societies in each state and by individuals across the country, an initiative which continues today [39]. This reflects the intention of the Parliamentary zone as a 'place of the people' while signifying the diversity of the country, its peoples, heritage and environments [39].

More recently, a National Arboretum was opened in 2013 across a 250-ha site to replace Pinus radiata plantations that contributed to devastating bushfires in 2003 that impacted the south-western suburbs of Canberra. A national design competition informed a master plan based on 100 monoculture mini-forests of rare, threatened and symbolic trees from Australia and the world. This arboretum has so far established 44,000 trees and is another significant tourist attraction and recreational resource [14].

The 'urban forest' of Canberra is a phrase used to describe the collective of trees within the city. It includes a diverse mixture of species, longevity and age classes, estimated in 2003 to comprise 400,000 trees of over 200 species [40]. Yet, some of the early planted 
exotic trees (e.g., poplars, Monterey Pines, willows, Celtis australis and Pistachia chinensis) are now classified under legislation as weed species and spread weed seeds into nature reserves. Similarly, many of the original exotic plantings are mature street trees and, in the harsh climate, are towards the end of their 'safe life' in an urban context [14,40]. This creates a modern dilemma about whether the form or type of plant is a heritage value worth protecting or whether its loss or replacement with native species is more appropriate in the contemporary context.

More broadly, more than 70\% of the Territory's 236,000 ha comprises national parks and nature reserves, far exceeding the Aichi Biodiversity Target of $17 \%$. An additional 6600 ha is public urban open space.

\section{Extent of Native Woodland, Ecosystem Values and Threats}

At the time of European settlement, around one-third of the Territory was grassland or river flats with the remaining area comprising native forests and woodlands [34]. Although woodlands were the dominant vegetation of the region, they now often persist only as small, degraded remnants. Only 25\% (i.e., 11,568 ha) of the extent of the main class (Yellow Box-Apple Box Grassy Woodland) prior to 1750 (i.e., pre-European settlement) remains. In contrast, there is less than $2 \%$ of Natural Temperate Grassland but around $99 \%$ of valley Snow Gum Woodlands remaining [41]. Although a substantial proportion (39\%) of the remnant woodlands occur on lands managed by state government for conservation purposes, the majority (61\%) are on rural lands, national land and other land managed primarily for other outcomes (Table 1).

Table 1. Remnant lowland woodland communities in the ACT. From [41].

\begin{tabular}{|c|c|c|c|c|c|c|}
\hline & & Extent & (Proportion) & by Tenure & Type * & \\
\hline Woodland Community & Total Extant, ha & $\begin{array}{c}\text { Nature } \\
\text { Reserve/National } \\
\text { Park, ha (\%) }\end{array}$ & $\begin{array}{c}\text { Other } \\
\text { Conservation, } \\
\text { ha (\%) }\end{array}$ & $\begin{array}{l}\text { Rural Leases or } \\
\text { Unleased Grazing } \\
\text { Licence, ha (\%) }\end{array}$ & $\begin{array}{l}\text { National Land- } \\
\text { Commonwealth } \\
\text { Managed, ha (\%) }\end{array}$ & Other, ha (\%) \\
\hline $\begin{array}{l}\text { Blakely's Red Gum-Yellow } \\
\text { Box Tall Grassy Woodland }\end{array}$ & 7196 & $2138(30)$ & $829(11)$ & $3129(43)$ & $621(9)$ & 477 (7) \\
\hline $\begin{array}{c}\text { Yellow Box-Apple Box Tall } \\
\text { Grassy Woodland }\end{array}$ & 4334 & $1289(30)$ & $251(6)$ & $2073(47)$ & $349(8)$ & $373(9)$ \\
\hline $\begin{array}{c}\text { Red Box Tall } \\
\text { Grass-Shrub Woodlands } \\
\text { Ribbon Gum Very Tall }\end{array}$ & 1776 & $359(20)$ & $317(18)$ & $709(40)$ & 335 (19) & $57(3)$ \\
\hline $\begin{array}{l}\text { Woodland on alluvial soils } \\
\text { along drainage lines }\end{array}$ & 174 & $155(89)$ & $7(4)$ & $6(3)$ & - & $6(4)$ \\
\hline $\begin{array}{l}\text { Snow Gum Grassy } \\
\text { Mid-high Woodland }\end{array}$ & 90 & $21(23)$ & $3(3)$ & $61(68)$ & - & $5(6)$ \\
\hline Total & 13,573 & $3963(29)$ & $1408(10)$ & $5978(44)$ & $1306(10)$ & $801(7)$ \\
\hline
\end{tabular}

* 'Other conservation' includes urban open spaces, special purpose reserves, hills, ridges and buffer lands and unleased areas managed to maintain natural values. 'Other' includes forests, roads, unleased land, Special Purpose Reserves managed for recreation, and private leased land.

Despite the loss of woodland across south-eastern Australia, the ACT contains some of the most intact woodland remnants, which are exceptional in their size, connectivity, diversity and habitat for threatened species. Many woodland areas have been lost in urban expansion, but others have been incorporated into nature reserves [36]. This includes significant remnants of the critically endangered Yellow Box-Blakely's Red Gum (Box-Gum) Woodland, which has reduced from 23\% to 9\% in the ACT between 1750 and 2000. There are no intact woodland landscapes remaining in the ACT and the patchy remnants are highly variable in condition and depauperate in habitat features such as hollows, logs and litter, particularly in urban areas [36]. Fortunately, the Territory's leasehold system discouraged the pasture improvement techniques (i.e., ploughing, fertilising and sown pastures) adopted in eastern Australia from the 1950s, which adversely impact the distribution and abundance of native plants [41].

Woodland trees are highly valued for landscape amenity and enhancing property values, leading to the retention of many large mature native trees within suburbs, parklands, road reserves, easements and on rural lands. Some local scattered Yellow Box 
(Eucalyptus melliodora) trees have been dated to over 300 years old [42]. Stands of trees and even isolated individual trees contribute to habitat connectivity for fauna, although the benefits are greater in larger stands and where the understory has been less modified by grazing [28]. However, urbanisation has fragmented the woodlands and created sharp habitat boundaries at the edge of nature reserves. It also increased recreation that impacts on some threatened species and various woodland birds that are in decline [36,41].

Ongoing threats to woodlands include urbanisation, overgrazing, inappropriate fire, invasive species, climate change and dieback [41]. Blakely's Red Gum (E. blakelyi) is particularly susceptible to dieback, but symptoms have been observed in eight Eucalyptus species in the ACT $[43,44]$. E. blakelyi is a dominant canopy species in Box-Gum Woodland. The species is at the limit of its thermal range in the ACT and vulnerable under the increasingly warm climate and increasingly consecutive years of stressful precipitation conditions during the growth season, based on 1940-2017 data [43]. Its decline has major implications for the viability of environmental offsets, created under national legislation to compensate for development impacts on this threatened ecosystem, and also because of the risk to the threatened Superb Parrot (Polytelis swainsonii) and other threatened birds that nest in E. blakelyi hollows. New plantings do not compensate for the ongoing loss of many mature and over-mature trees or tree hollows, which take over a century to form [14,44].

An evaluation of changes in urban mature trees between 2004 and 2015 showed that suburban development initially causes a marked decrease in mature tree canopy cover, presumably largely of native trees, although with gains of younger and possibly primarily non-native tree species in gardens and road verges (Table 2). Canopy cover was analysed by the ACT Government using 2004 SPOT-5 satellite imagery and 2015 LiDAR (Light Detection and Ranging) aerial-imaging data for several early established suburbs, recently established suburbs, nature reserves and rural areas of the ACT [45]. Notable was the considerable gain of tree cover and number in most of the analysed rural areas and nature reserves. This may be due partly to environmental plantings as well as reduced livestock impacts on regeneration. It would be valuable to assess in more detail the relative gain and loss of native trees across the tenure types, and particularly of mature native trees. Detailed ground surveys and mapping are needed to distinguish native from exotic trees, but the mapping provides a robust baseline for future analyses of tree cover change.

Table 2. Changes in trees and mature tree cover, 2004-2015. From [45].

\begin{tabular}{ccccccc}
\hline & $\begin{array}{c}\text { 2004 Tree } \\
\left.\text { Cover } \mathbf{( m}^{\mathbf{2}}\right)\end{array}$ & $\begin{array}{c}\text { 2015 Tree } \\
\left.\text { Cover } \mathbf{( m}^{\mathbf{2}}\right)\end{array}$ & $\begin{array}{c}\text { No. of } \\
\text { Trees Lost }\end{array}$ & $\begin{array}{c}\text { No. of } \\
\text { Trees Gained }\end{array}$ & $\begin{array}{c}\text { Change in } \\
\text { Cover (ha) }\end{array}$ & $\begin{array}{c}\text { Tree Cover } \\
\text { Change (\%) }\end{array}$ \\
\hline 4 'new' suburbs & 554,277 & 482,373 & 742 & 166 & -7.2 & -12.97 \\
4 'older' suburbs & $2,076,676$ & $2,098,911$ & 744 & 819 & +2.0 & +1.07 \\
3 nature reserves & $2,568,743$ & $2,741,814$ & 271 & 1239 & +17.31 & +6.74 \\
4 rural areas & $7,350,240$ & $7,794,524$ & 694 & 2523 & N/A * & +6.00 \\
\hline
\end{tabular}

* N/A not calculated.

\section{Current Programs and Initiatives}

A range of policy and legislative mechanisms direct environmental outcomes in the ACT at a state level while Commonwealth Government imperatives provide planning controls over Commonwealth land (e.g., designated land and defence land) within the ACT. The key mechanisms relevant to tree conservation and protection encompass statutory planning, biodiversity conservation, cultural heritage conservation and climate change impact mitigation (Table 3). Importantly, the ACT Planning Strategy continues the vision of Canberra being a city within the landscape that celebrates its bushland setting [14]. 
Table 3. Regulatory mechanisms in the ACT relevant to tree conservation. The policies with specific tree-related targets are in bold.

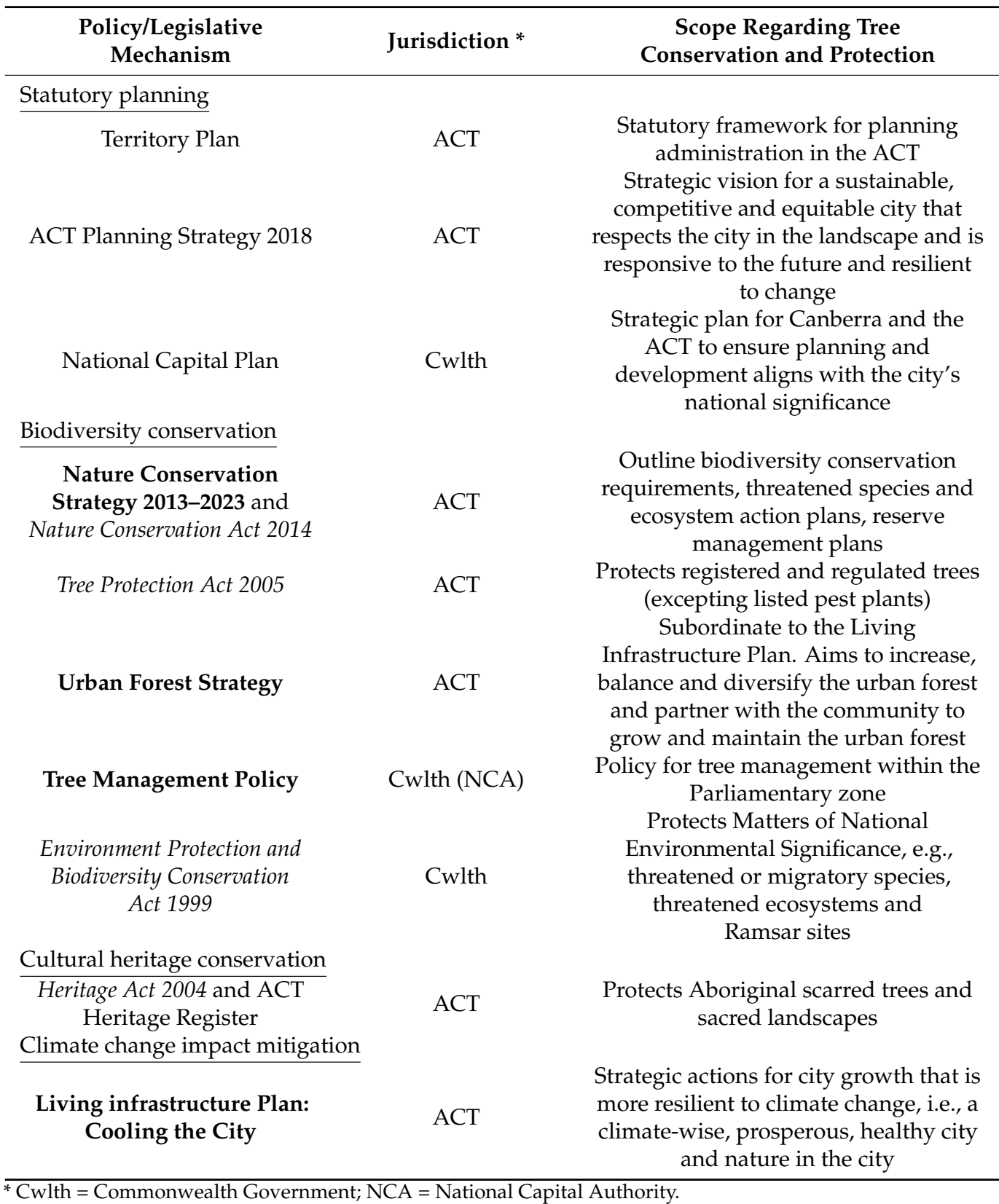

The key ACT policies with specific tree-related targets or a focus on forest condition and biodiversity outcomes are the Nature Conservation Strategy, the Urban Forest Strategy and the Living Infrastructure Plan. Collectively, these policies aim to conserve the city's landscape and biodiversity, address key threatening processes such as the loss of mature native trees, address urban heat and urban sprawl, and engage the community in recreational use, appreciation, growth and maintenance of living infrastructure. Similarly, the National Capital Authority drafted a Tree Management Policy in 2021 to ensure that landscape maintenance plans on Commonwealth-controlled land integrate tree and heritage management planning for the national benefit.

Considerable work is occurring towards these aims and achieving sustainable development outcomes. It includes (i) regulatory update, (ii) inventory, (iii) mapping, (iv) asset valuation and management, (v) research and (vi) stakeholder engagement. 


\subsection{Regulatory Renewal}

A review and reform through 2019-2022 of the ACT's planning system will lead to revised planning legislation, a new Territory Plan and new district strategies that determine the city's development and the government's aspirations for its growth. The intended outcomes are to deliver a liveable, sustainable, resilient and diverse Territory for future generations.

In parallel, a review and update of the ACT's Tree Protection Act 2005 is underway. This will increase focus on tree protection and conservation issues (e.g., tree habitat values) rather than the current emphasis on regulating removal [14]. The new Urban Forest Bill will work alongside a draft variation to the Territory Plan (DV369) to increase protection on leased land for existing canopy trees including safe mature native trees, while making room for trees during development and ensuring that canopy trees approved for removal are replaced with new plantings. The draft variation proposes higher requirements for minimum planting area, along with new requirements for plantings. The Living Infrastructure Plan aims to increase tree canopy cover (or equivalent) to $30 \%$ and ground-surface permeability to $30 \%$ across the urban area by 2045 . Urban canopy cover is on track towards the target, being estimated as $22.5 \%$ in 2020 . The extent of permeable surfaces in urban Canberra has been estimated as $42 \%$, already exceeding the target at a large-scale; however, issues with stormwater flooding, waterway pollution and altered hydrology in reserves near urban development show that further research and finer-scale assessment is needed to reduce these impacts.

The Urban Forest Bill assists in landscape protection by encouraging brownfield rather than greenfield development through a 70\% urban infill target. In addition, an action plan has been prepared to address the loss of mature native trees (including hollow-bearing trees). Lack of recruitment has been recognised as a key threatening process under the Nature Conservation Act 2014 with impacts on at least four threatened birds. The action plan aims to protect existing mature native trees, increase recruitment and survival of young native trees, and enhance the ecological context of mature and young native trees.

\subsection{Inventory}

Identification of natural assets such as mature native trees, regulated and registered trees, and culturally significant trees is essential to guide onground management and prevent inadvertent damage and loss. On land managed by Transport Canberra and City Services, an asset management system is expanding to include public urban trees. Similarly, the Environment, Planning and Sustainable Development Directorate is developing spatial databases and asset systems for recording values including significant trees in the nature reserve and national park estate. There are now an estimated 770,000 trees on leasehold land in Canberra and a similar number on public land.

A cultural heritage database is also being developed, but conversations are needed about how best to manage intangible as well as tangible heritage. For example, conservation of some trees of significance to the Ngunawal Traditional Custodians requires that line of sight be maintained between the tree and other landscape features [46].

\subsection{Mapping}

SPOT-5 satellite imagery and LiDAR aerial-imaging data are being used to develop a tree canopy coverage and canopy height model for the ACT. The identification and mapping of mature and remnant native trees will assist with native tree protection in urban areas under the Urban Forest Strategy. The 2020 LiDAR data are being used to track progress towards the $30 \%$ urban canopy cover target.

The LiDAR data also provided underpinning evidence to the ACT Scientific Committee about the loss of mature native trees across the Territory, which assisted in the listing of the Loss of Mature Native trees as a Key Threatening Process under the Nature Conservation Act. Studies of dieback in the critically endangered Box-Gum Woodland across the Territory also drew on LiDAR imagery from 2004 to 2017 and were able to establish measurable 
changes in woodland condition through time $[43,47]$. These analyses will be revisited with later data to better understand dieback trends and risks to offsets with susceptible Eucalyptus species.

\subsection{Asset Valuation and Management}

More broadly, the use of environmental economic accounting is being explored in the $\mathrm{ACT}$ as a tool to analyse development issues, assess policy options and promote decision making that incorporates the stocks and flows of environmental assets and the consequential benefits and beneficiaries of those flows. Preliminary work has been undertaken on water accounts and for state of environment reporting, and is proposed for biodiversity assets in an urban development context.

The ACT's target for increased urban canopy cover aims to assist with mitigating local impacts of climate change. Discussions are ongoing about canopy cover equivalence such that other green/blue infrastructure (e.g., green rooves, shrub beds, wetlands and rain gardens) could contribute to achieving this target. A key challenge is to match site and landscape context to appropriate species form, and leaf characteristics to the climatic imperative; for example, deciduous non-native trees in sites needing summer shade also reduce air temperatures, local native species enhance habitat connectivity to reserves, and native groundcover plants beneath native trees in suburban parks support tree condition but also reduce maintenance costs. The choice between native and non-native trees is not clear-cut; shade from some deciduous trees can reduce air temperatures up to $15^{\circ} \mathrm{C}$ on hot days but the trees may not be drought and heatwave resistant [48].

The ACT Government works with key stakeholders and the community to retain as many trees as possible. The Canberra Tree Network brings together ACT and national government staff with representatives from neighbouring councils, universities, the government nursery, Parliament House, the National Botanic Gardens and the National Arboretum to share information about programs and Tree Week activities. Within the urban leasehold land context, the Government has trained staff to create hollows in standing dead trees to alleviate the loss of these features from development. Nevertheless, in 2018/19, 1731 tree removal applications were approved from 2320 submissions.

\subsection{Research}

A Tree Canopy Equivalence Tool and methodology was developed to calculate the equivalence of alternate blue/green infrastructure to trees and shrubs of over $3 \mathrm{~m}$ height. This research built on the mapping of other living infrastructure types to quantify the benefits and equivalence of ten disparate forms of living infrastructure. However, the results were constrained due to limited input data. Importantly, such a tool may cause perverse policy outcomes such as where exotic lawn with a high level of equivalence may overwhelm the tree canopy target. It is critically important that the environmental (and socio-cultural) benefits of native species are maximized wherever possible given their overall decline and the threatened status of some native species and ecosystems.

Similarly, the social and heritage benefits of exotic trees in the urban context need to be considered in light of their impact on native ecosystems. For example, many of Canberra's waterways have water quality problems and the LiDAR-derived maps of urban tree cover density can be used to assess leaf litter deposition and the associated adverse impacts of nutrient loads on waterways.

The mapping of mature native trees will be used as part of critical habitat identification and mapping for hollow-dependent threatened bird species such as the Superb Parrot and Gang-Gang Cockatoo (Callocephalon fimbriatum). Research on the ecology and flight paths of these species using GPS trackers on birds will assist in understanding the importance of particular trees in the landscape. When incorporated with climate change projections, these data can inform where habitat supplementation (e.g., tree plantings, created hollows and provision of nest boxes) and additional conservation to ensure landscape-scale habitat connectivity are needed. Experimental research on the benefits of dead mature trees has led 
to their increased retention and the reinstatement of some that were removed from urban development sites into offset reserve areas.

\subsection{Stakeholder Engagement}

Given the losses of mature trees across the urban area, planting is an essential component of achieving the $30 \%$ tree canopy cover target. The ACT Government is planting 54,000 trees between 2020 and 2024. It provides support to three catchment coordination groups for ecosystem restoration and offers grants to over 60 community groups and stakeholders through environment grants and 'nature in the city' grants. Community representatives are able to discuss concerns and government planning through a Biodiversity Conservation Forum initiated in 2021. National government funding is also contributing to protecting and connecting endangered woodlands.

Demonstration sites and information dissemination contribute to an informed population. The Whitlam Display Village is trialing innovative living infrastructure solutions including passive irrigation, permeable driveway surfaces and street tree planting. A Climate-wise Landscape Guide is being prepared to assist developers and homeowners create climate-wise landscapes, while government-commissioned research informed publicly available standards identifying trees that are suitable in a climate change context.

One community-led project in late-2019 transformed a small urban 'pocket' park in south-western Canberra. The park is a remnant of Box-Gum Woodland with several 200-300 year old trees. Its landscape location suggests that it was a damp biodiverse woodland gully prior to European settlement. However, heavy infestation with invasive exotic grasses (African Lovegrass Eragrostis curvula, Chilean Needle Grass Nassella neesiana) led an influential government advisor to consider the site too degraded to warrant restoration.

Nevertheless, the local community persisted and received a small AU\$12,500 government grant. They used the funds to manually remove invasive grasses, solarise soil to kill the weed seedbank, and create wide, shallow berms and swales around contours using treated soil to slow water movement and increase water retention on site. An excavator was brought in to experiment with methods for weed seedbank removal and reducing soil compaction to increase plant rooting depth. A rock flume was created to redirect stormwater from upslope impermeable surfaces (i.e., roads and footpaths) into the park as an ephemeral creek with plantings of native groundcover species to filter pollutants.

The revegetation focused on restoration of the structure and composition of the original understory of the woodland, changing the soil nutrient status to favour native rather than exotic plants, and repairing hydrological function. Planting of rows of native sedges within the dripline of old native trees created a pedestrian barrier and an area for retention of fallen timber, which is perceived as a risk by some members of the community. The actual risk of harm due to tree failure in Canberra is very low, around 1 in 15,000,000 deaths due to accidental tree failure and 1 in 189,000,000 deaths inside a house from tree failure, compared to 1 in 20,000 from driving and 1 in 13,500 from melanoma [49]. However, responding to this health and safety issue alleviated local concerns. After only two years, there is an increased number of native butterflies and birds on site and native shrub and tree seedlings emerging from the remnant soil-stored seedbank; meanwhile, invasive grasses are very limited in treated areas.

The overarching intention was to develop a method that could be applied in other parks. The project initiator trialed research and novel restoration methods in keeping with the urban context and the social and economic limitations of urban sites. This included how the community used the area, the presence of underground and above-ground utilities, and the need for cost-effective maintenance. The community responded by volunteering their time and labour to the project and ongoing maintenance because they understood its value. This created greater neighbourhood connection, ownership of the project and interest in the site with residents reporting noticeable cooling effects and mental health benefits. 'Cues to care' were used, including signage, flowering plants and patterns of mown grassed walkways, which signal intentional human maintenance and valuing of 
the site [50]. They create opportunities for challenging a culturally aesthetic paradigm of manicured trees with a mown grass understory. In providing something familiar and recognisable, they allow people to learn to value the unfamiliar beauty and function of complex habitat structures.

The project highlights the importance of community engagement, education and directly addressing the costs and externalities of suboptimal practices. Constant mowing damages hydrological processes, is costly, and unsanitized equipment has spread ecologically transforming weeds [14]. Meanwhile, risk-averse perspectives about accidental tree failure contributed to the removal of many mature and hollow-bearing trees [14]. Championing alternative approaches focused on restoring ecological function provided cost-effective social and biodiversity conservation outcomes.

\section{Discussion and Conclusions}

Human agency and relationships with the environment of the Canberra region are inherent, essential elements in its changing landscape from pre-European to present times. By focusing on treed ecosystems, we can understand the city and its landscape as an evolving process of interactions between nature and culture, tangible and intangible heritage, that have created the special character or genius loci of the city [1]. Canberra is a uniquely planned, idealized city $[1,18]$ in a landscape with an active human presence of at least 25,000 years, a landscape that represents a palimpsest with an archive of messages about the past [26]. Deliberative engagement with this landscape has been a primary influence at a diffuse level for thousands of years and at a documented intensive level for just over 100 years. Through the four temporal phases described here for the Canberra region, there have been various indicators of these culture-nature relationships, some of which are common amongst the phases.

Firstly, the tree-dominated ecosystems have been altered substantially by people, for tangible and intangible outcomes. Early settlers extensively cleared local woodlands to enhance areas for stock grazing and utilized timber resources for fencing and housing. Most of the trees that they planted were familiar European species, reminiscent of their origins and in keeping with colonial planting preferences. Later, city planners, officials and residents introduced extensive numbers and types of tree species to enhance landscape aesthetics and provide shelterbelts, greenways, urban parks and gardens for environmental and recreational purposes. Many of these trees also were European or North American species, particularly in formalized plantings. Despite some early interest in the horticultural use of local native plants, it was not until the 1970-1980s that they dominated some suburban and iconic area plantings in the Parliamentary zone. The First Nations people, the Ngunawal, also manipulated local forests through deliberate use of fire to enhance utilitarian needs, such as food and material resources, and create accessible pathways across the landscape. Some trees also held intangible values for Ngunawal people; for example, signifying connections between culturally significant landscape features.

A second indicator of this cultural landscape is in the various, often overlapping ways in which people have related to elemental features: topography, ecotones and sunlight. Major topographical features including mountains were named by Ngunawal people and many had ceremonial or spiritual importance [26]; for example, Mt Ainslie is a culturally significant women's place for Ngunawal women and Black Mountain is a culturally significant men's place for Ngunawal men. The mountains, hills and ridges also were intrinsic elements of Griffin's design for the cityscape. Similarly, waterways represented pathways for Ngunawal people with many culturally important sites nearby, and were the first areas to be settled by Europeans. Ecotones such as land and water junctions were richest in resources [26,27]. Moreover, the lake formed from damming of the Molonglo River shows this temporal continuity of the importance of the water-land interface-it was the centrepiece of the city's design and is now a major recreational, aesthetic, social and touristic resource, with increasing multi-storey residential developments adjacent. Another aspect of this theme is sunlight, which is explicitly accounted for in Griffin's municipal 
planning but also important traditionally to Ngunawal people. Ngunawal sites occur across the landscape and Kabaila [26] considered that their only predictable characteristics are that campsites are likely to occur on gentle slopes with a north-western to north-eastern aspect, thereby maximising sunlight.

Thirdly, Canberra is the seat of government but the site of Parliament House was also a major meeting place for multiple Aboriginal language groups. Likewise, there are other monuments or important infrastructure now located on sites that were significant to Ngunawal people (e.g., the Botanic Gardens is on a former corroboree ground and a nearby university oval was a hunting ground [31]). An overlay of human movement has also occurred, with Ngunawal pathways being used by stockmen and explorers, and many later being converted to European roadways [26].

This rich history of human engagement and overlays of inter-relationships with, and modifications of, the local landscape reflect an evolution of social values, needs and ecological connections that have sustained people in different but similar ways. The nature-culture connection has become embedded throughout the city's parks and open space as a consequence of considered legislation and design planning [14,21,34]. Yet, ongoing population growth, suburban expansion, urban densification, resource demands, biodiversity loss and climate change are imposing considerable pressures on the bushland and grasslands, landscape setting and connectivity of ecosystems. Some argue that recent governments have compromised the landscape, sustainable planning outcomes and the original design philosophy in preference for economically oriented objectives including job growth and urban densification (e.g., $[14,17,19,26])$. Since self-government in 1988, new suburbs have largely comprised small urban plots dominated by large houses with little green space, mature trees, soil permeability or native species habitat, and high-rise buildings, without regard for the historic landscape $[1,26]$.

While densification and consolidation do reduce pressure on the city's surrounding natural environment, they challenge the feasibility of protecting adequate natural landscape, biodiversity values and native species' habitat corridors throughout the cityscape as well as the landscape and the cultural heritage that is intrinsic to its character [1]. Biodiversity and cultural heritage conservation are underlain by national and state-level policy and legislation. However, it is recognised that maintaining the current density of urban development (i.e., 1080 residents per $\mathrm{km}^{2}$ ) for a projected population even of 600,000 in 2041 is ecologically unsustainable, inefficient with regard to sustainable transport, and increases pressures on agricultural land and environmentally sensitive areas [12]. Additionally, the population is highly transient and around half of the population growth is from overseas migration, and thus, inhabitants are potentially unfamiliar with local landscape values. Nevertheless, the high proportion and usage of Canberra's urban reserves, the latter particularly notable during the COVID-19 pandemic, as well as a high level of community volunteerism and restoration initiatives and government policies and programs (see [14]) demonstrate a growing willingness and commitment to experience and retain the city's landscape character and natural values.

Achieving biodiversity and cultural heritage conservation is dependent on collective, collaborative efforts across government, stakeholders and the community. Some of the planning mechanisms relate to ACT and some to Commonwealth objectives, and because there are multiple agencies within ACT Government with primary responsibility for these mechanisms, there is a need for deliberative review and integration to facilitate optimal outcomes across the breadth of intended approaches and complementarity of actions. Even within ACT Government, trees within a reserve and national park context are managed by the Environment, Planning and Sustainable Development Directorate whereas trees within an urban context are managed by Transport Canberra and City Services unless the trees are on national land, where they are managed by the National Capital Authority. The defence estate is managed separately again. Issues around infrastructure maintenance (e.g., pipes, electricity and telecommunications cables) also draw in the perspectives of utility organisations [14]. Coordination, communication and transparency across agencies, 
government advisory and scientific committees, and research partners are, therefore, critical to effective outcomes-based decision making, as is commitment to best-practice approaches, long-term outcomes and maintenance of the urban forest and its natural and cultural values [14].

Community engagement and stewardship in valuing, growing and maintaining the city's vegetation is another key aspect to achieving optimal biodiversity as well as social and economic outcomes. As demonstrated in the pocket park restoration example, community leadership can result in novel or experimental approaches that achieve unexpectedly good outcomes including a sense of community empowerment and connection [14]. Although a 'small win', strategic planning for community stewardship could be part of transformative macro-level changes towards sustainability [7]. Strong interest in the urban forest is already evident through a citizen's forum in 2018 that ranked street and park trees as the second highest priority among 14 municipal services [14]. The government policy intent is for all residents to have access to nature within a kilometre of their home in recognition of the benefits for health and wellbeing, as well as the social and economic benefits. This is supported by research from Japan showing the linkage between local green spaces and longer life expectancy [14]. However, it is paramount to address quality as well as quantity of green space [14], particularly as urban infill progresses.

The intangible associative values now valued by many Canberran residents are a key part of a cultural landscape but also central to the deep relationship between First Nations people and their Country (landscape) [1]. The relationship of people and natural elements is part of the identity of a place and an inclusive sense of belonging, which can be experienced such as for tourism purposes but can also inspire people's attachment and desire to live in a place or as part of a community [1]. As a young city of just over 100 years old, with a populace that is highly transitory and dominated by people born elsewhere, there is a need to build a sense of connection to the city and landscape amongst Canberra's residents. In this, there is a clear opportunity to engage at a deeper level with a traditional Ngunawal perspective that emphasises personal experience and perception grounded in the inseparability of mind, body and environment [37]. Incorporation of an ecosystem approach, long-term intergenerational outcomes and First Nations peoples' cultural rights are embedded within our international biodiversity conservation frameworks. It may be that this custodial approach, focused on stewardship of natural and cultural values, is the missing ingredient in ensuring the city's ecological sustainability and long-term biodiversity conservation outcomes. An integrative policy could be developed for the Territory that acknowledges the nature-culture connections across urban and non-urban spaces, and clarifies the past, present and future needs and values of people in the landscape and how to best achieve them.

In conclusion, deliberative planning has been foundational in creating an exemplary city of global significance designed to integrate the natural values of the landscape's hills, ridges and valleys with the city's design, built infrastructure, cultural intentions, aesthetics and societal outcomes. This review demonstrates the considerable interface between culture and nature through human agency on landscape elements, and specifically the intentional modification of treed ecosystems for particular objectives. Through time, there have been differential relationships of people to the landscape including the importance of natural values. Strong visionary leadership is now imperative to reconcile the current diversity of visions and approaches. A landscape-level policy could optimise outcomes by embedding an ecological and Ngunawal sensibility in future planning. The heritage values can be respected while protecting the natural and cultural values that designate the city as the nation's Bush Capital and influenced Canberra being identified by the OECD in 2014 to 2020 as the world's most liveable region [51] based on 11 indicators of wellbeing, including life satisfaction and environment. Key challenges relate to progressing an innovative, integrated approach that encompasses all natural and green spaces in the Territory, their values, and their socio-cultural importance. Imperative in this is coordination and engagement across all relevant groups with interests and responsibilities in particular locations, and building 
connection amongst all residents to the city's landscape and values. Nature and culture need to be deeply understood to be well managed [14] (p. 67), the facilitation of which goes beyond passive education and engagement, towards engendering a stewardship ethic and attachment to a place (or city) and its landscape.

Funding: This research received no external funding.

Acknowledgments: The author acknowledges the Ngunawal Traditional Custodians and their Elders past, present and future on whose land I live and work. The article benefited from the input of Ngunawal Traditional Custodians Wally Bell, Karen Denny and Mary Mudford, and various published literature referring to Ngunawal culture and landscape relationships. The article also draws on extensive programs in the ACT Government related to biodiversity conservation and living infrastructure planning. The author thanks Johannes Botha for information about tree canopy cover analyses in the ACT, and Alice Hathorn for her generous engagement and information about the Fowles Street Park restoration project. The author also thanks the academic editor, two anonymous reviewers, Åsa Ferrier, Bob Beeton and Karen Williams for their comments and advice, which improved the manuscript.

Conflicts of Interest: The author declares no conflict of interest.

\section{Note}

Australian First Nations languages are oral rather than written so spelling of words varies in written records. The author uses 'Ngunawal' here as the preference of her key contacts and as used in some of the referenced literature. 'Ngunnawal' is an alternative spelling preferred by some other local Traditional Custodians and the ACT Government.

\section{References}

1. Taylor, K. Cities as cultural landscapes. In Reconnecting the City: The Historic Urban Landscape Approach and the Future of Urban Heritage; Bandarin, F., Van Oers, R., Eds.; Wiley-Blackwell: Chichester, UK, 2015; pp. 179-202.

2. Williams, M. Ecology, imperialism and deforestation. In Ecology \& Empire; Griffiths, T., Robin, L., Eds.; Melbourne University Press: Melbourne, Australia, 1997; pp. 169-184.

3. Butchart, S.H.M.; Walpole, M.; Collen, B.; van Strien, A.; Scharlemann, J.P.W.; Almond, R.E.A.; Baillie, J.E.M.; Bomhard, B.; Brown, C.; Bruno, J.; et al. Global biodiversity: Indicators of recent declines. Science 2010, 328, 1164-1168. [CrossRef] [PubMed]

4. Whitehorn, P.R.; Navarro, L.M.; Schröter, M.; Fernandez, M.; Rotllan-Puig, X.; Marques, A. Mainstreaming biodiversity: A review of national strategies. Biol. Conserv. 2019, 235, 157-163. [CrossRef] [PubMed]

5. Olsson, P.; Folke, C.; Hughes, T.P. Navigating the transition to ecosystem-based management of the Great Barrier Reef, Australia. Proc. Natl. Acad. Sci. USA 2008, 105, 9489-9494. [CrossRef] [PubMed]

6. Beeton, R.J.S.; Lynch, A.J.J. Most of Nature: A framework to resolve the twin dilemmas of the decline of nature and rural communities. Environ. Sci. Policy 2012, 23, 45-56. [CrossRef]

7. McNeely, J.A. Conserving biodiversity: The key political, economic and social measures. In Biodiversity, Science and Development: Towards a New Partnership; di Castri, F., Younès, T., Eds.; CAB International: Wallingford, UK, 1996; pp. $264-281$.

8. Cowling, R.M.; Egoh, B.; Knight, A.T.; O’Farrell, P.J.; Reyers, B.; Rouget, M.; Roux, D.J.; Welz, A.; Wilhelm-Rechman, A. An operational model for mainstreaming ecosystem services for implementation. Proc. Natl. Acad. Sci. USA 2008, 105, 9483-9488. [CrossRef] [PubMed]

9. Folke, C.; Polasky, S.; Rockström, J.; Galaz, V.; Westley, F.; Lamont, M.; Scheffer, M.; Österblom, H.; Carpenter, S.R.; Chapin, F.S., III; et al. Our future in the Anthropocene biosphere. Ambio 2021, 50, 834-869. [CrossRef] [PubMed]

10. Jacobson, C.; Hughey, K.F.D.; Lynch, A.J.J.; Nursey-Bray, M.; O'Connell, M.; Munro, P.G.; Vella, K.; Whiley, D.; Dovers, S.; Carter, R.W. Twenty years of pacifying responses to environmental management. Australas. J. Environ. Manag. 2014, 21, 143-174. [CrossRef]

11. Ruckelshaus, M.; McKenzie, E.; Tallis, H.; Guerry, A.; Daily, G.; Kareiva, P.; Polasky, S.; Ricketts, T.; Bhagabati, N.; Wood, S.A.; et al. Notes from the field: Lessons learned from using ecosystem service approaches to inform real-world decisions. Ecol. Econ. 2015, 115, 11-21. [CrossRef]

12. ACT Government. ACT Climate Change Strategy 2019-25; ACT Government: Canberra, Australia, 2019.

13. Watson, F.K. A Brief History of Canberra-The Capital City of Australia; Federal Capital Press: Canberra, Australia, 1927.

14. Standing Committee on Environment and Transport and City Services (SCETCS). Inquiry into Nature in Our City. 2020. Available online: https: / / www.parliament.act.gov.au/_data/assets/pdf_file/0005/1480091/9th-ETCS-10-Inquiry-into-Nature-in-OurCity.pdf (accessed on 13 November 2021).

15. Fitzgerald, A. Historic Canberra 1825-1945. A Pictorial Record; Griffin Press: Salisbury, Australia, 1977.

16. Murphy, G.P. Parks and Gardens in Canberra. Origins and Foundation 1911-20, Thirty Green Years 1921-51; Department of the Capital Territory: Canberra, Australia, 1979. 
17. Freestone, R. Canberra's gardens, parks, and landscape: A bibliographical essay. Aust. Gard. Hist. 2013, $24,5-11$.

18. Griffin, W.B. The Federal Capital. Report Explanatory of the Preliminary General Plan; Government Printer: Melbourne, Australia, 1913.

19. Claoué-Long, A. Cultivating a capital city. Canberra Hist. J. 2020, 85, 13-23.

20. MacKenzie, A.; Sumartojo, S. Narratives of Sustainability in the Urban Landscape: Canberra's National Capital Open Space System (NCOSS); World in Denmark: Copenhagen, Denmark, 2012.

21. National Capital Development Commission (NCDC). The Future Canberra; Angus \& Robertson: Sydney, Australia, 1965.

22. Flood, J.; David, B.; Magee, J.; English, B. Birrigai: A Pleistocene site in the south-eastern highlands. Archaeol. Ocean. 1987, 22, 9-26. [CrossRef]

23. Theden-Ringl, F. Aboriginal presence in the high country: New dates from the Namadgi Ranges in the Australian Capital Territory. Aust. Archaeol. 2016, 82, 25-42. [CrossRef]

24. Argue, D. Aboriginal occupation of the Southern Highlands: Was it really seasonal? Aust. Archaeol. 1995, 41, 30-36. [CrossRef]

25. Gillespie, L.L. Aborigines of the Canberra Region; Lyall L. Gillespie: Canberra, Australia, 1994.

26. Kabaila, P.R. Belconnen's Aboriginal Past; Black Mountain Projects: Canberra, Australia, 1997.

27. Boot, P.; Kuskie, P. Consultancy and thesis-What's the difference? Two approaches to archaeological survey of Jumping Creek Valley, Queanbeyan. Aust. Archaeol. 1996, 43, 23-28. [CrossRef]

28. Ingwersen, F.; Goodisson, T.; Ormay, P.; Woodward, S.; Morris, B. Woodland in the ACT Sector of the South East Highlands Division of the Interim Biogeographic Regionalisation of the Australia; ACT Parks and Conservation Service: Canberra, Australia, 1997.

29. Cahir, F.; Clark, I.D.; Clarke, P.A. Aboriginal Biocultural Knowledge in South-Eastern Australia; CSIRO Publishing: Melbourne, Australia, 2018.

30. Gugler, A. A Story of Capital Hill; Elect Printing: Canberra, Australia, 2009.

31. Bell, W.; Buru Ngunawal Aboriginal Corporation, Canberra, ACT, Australia. Personal Communication, 2018, 2022.

32. Meyers, D. Lairds, Lags and Larrikins. An early History of the Limestone Plains; Sefton Publications: Canberra, Australia, 2010.

33. Martin, G. Episodes of Old Canberra; ANU Press: Canberra, Australia, 1978.

34. Hendry, M.J. Canberra-A city within the landscape. An evaluation of the provision of parkland and public open space. Landsc. Plan. 1979, 6, 271-283. [CrossRef]

35. Ingwersen, F.; Evans, O.; Griffiths, B. Vegetation of the Ainslie-Majura Reserve; Australian Government Publishing Service: Canberra, Australia, 1974.

36. Environment ACT. Woodlands for Wildlife. ACT Lowland Woodland Conservation Strategy; Action Plan No. 27; Environment ACT: Canberra, Australia, 2004.

37. Williams, K. An Emergent Methodology for Creating a Transcultural Spatial Narrative. Ph.D. Thesis, University of Canberra, Canberra, Australia, 2011.

38. National Museum of Australia. Defining Moments-'Federation' Wheat. 2021. Available online: https://www.nma.gov.au/ defining-moments/resources/federation-wheat (accessed on 4 November 2021).

39. Howe, A. Planting democracy in Canberra's Parliamentary Triangle. Aust. Gard. Hist. 2021, 32, 9-12.

40. Banks, J.C.G.; Brack, C.L. Canberra's urban forest: Evolution and planning for future landscapes. Urban For. Urban Green. 2003, 1, 151-160. [CrossRef]

41. Environment, Planning and Sustainable Development Directorate (EPSDD). ACT Native Woodland Conservation Strategy and Action Plans; EPSDD: Canberra, Australia, 2019.

42. Banks, J.C.G. Tree ages and ageing in yellow box. In The Coming of Age: Forest Age and Heritage Values; Dargavel, J., Ed.; Australian Heritage Commission: Canberra, Australia, 1997; pp. 17-28.

43. Cowood, A.L.; Lynch, A.J.J.; Botha, J.; University of Canberra, Canberra, Australia. Blakely's Red Gum Dieback in the ACT. 2018, Unpublished Report to ACT Government.

44. Lynch, A.J.J.; Botha, J.; Johnston, L.; Peden, L.; Seddon, J.; Corrigan, T. Managing a complex problem: Blakely's Red Gum Dieback in the ACT. In Proceedings of the Restore, Regenerate, Revegetate: A Conference on Restoring Ecological Processes, Ecosystems and Landscapes in a Changing World, University of New England, Armidale, Australia, 5-9 February 2017; Smith, R., Ed.; 2018; pp. 51-52.

45. Botha, J.; University of Canberra, Canberra, Australia. Mature Tree Canopy Cover Change in the ACT, 2004-2015. 2018, Unpublished Report, ACT Government.

46. Mudford, M.; EPSDD, ACT Government, Canberra, ACT, Australia. Personal Communication, 2021.

47. Botha, J.; EPSDD, ACT Government, Canberra, Australia. 2021, Unpublished data.

48. Schuldt, B.; Buras, A.; Arend, M.; Vitasse, Y.; Beierkuhnlein, C.; Damm, A.; Gharun, M.; Grams, T.E.E.; Hauck, M.; Hajek, P.; et al. A first assessment of the impact of the extreme 2018 summer drought on Central European forests. Basic Appl. Ecol. 2020, 45, 86-103. [CrossRef]

49. Hartley, M.A.; Chalk, J.J. A Review of Deaths in Australia from Accidental Tree Failures. 2019. Available online: https: / / arboriculture.org.au/education/database-of-australian-fatalities-caused-by-tree-failures (accessed on 9 November 2021).

50. Nassauer, J.I. Messy ecosystems, orderly frames. Landsc. J. 1995, 14, 161-170. [CrossRef]

51. Current Quality of Life Index. Available online: https://www.numbeo.com/quality-of-life/rankings_current.jsp (accessed on 2 November 2021). 